\title{
In vitro indications for favourable non-additive effects on ruminal methane mitigation between high-phenolic and high-quality forages
}

\author{
Anuraga Jayanegara ${ }^{1,2}$, Svenja Marquardt ${ }^{1}$, Elizabeth Wina $^{3}$, Michael Kreuzer ${ }^{1}$ and Florian Leiber $^{1 *}$ \\ ${ }^{1}$ ETH Zurich, Institute of Agricultural Sciences, Universitaetstrasse 2, 8092 Zurich, Switzerland \\ ${ }^{2}$ Department of Nutrition and Feed Technology, Faculty of Animal Science, Bogor Agricultural University, Bogor 16680, \\ Indonesia \\ ${ }^{3}$ Indonesian Research Institute for Animal Production, PO Box 221, Bogor 16002, Indonesia \\ (Submitted 2 November 2011 - Final revision received 19 March 2012 - Accepted 2 April 2012 - First published online 28 May 2012)
}

\begin{abstract}
Feeding plants containing elevated levels of polyphenols may reduce ruminal $\mathrm{CH}_{4}$ emissions, but at the expense of nutrient utilisation. There might, however, be non-additive effects when combining high-phenolic plants with well-digestible, high-nutrient feeds. To test whether non-additive effects exist, the leaves of Carica papaya (high in dietary quality, low in polyphenols), Clidemia hirta (high in hydrolysable tannins), Swietenia mahagoni (high in condensed tannins) and Eugenia aquea (high in non-tannin phenolics) were tested alone and in all possible mixtures ( $n 15$ treatments). An amount of $200 \mathrm{mg}$ DM of samples was incubated in vitro ( $24 \mathrm{~h}$; $39^{\circ} \mathrm{C}$ ) with buffered rumen fluid using the Hohenheim gas test apparatus. After the incubation, total gas production, $\mathrm{CH}_{4} \mathrm{concentration}$ and fermentation profiles were determined. The levels of absolute $\mathrm{CH}_{4}$, and $\mathrm{CH}_{4}$ :SCFA and $\mathrm{CH}_{4}$ :total gas ratios were lower $(P<0 \cdot 05)$ when incubating a combination of $C$. papaya and any high-phenolic plants ( $C$. hirta, S. mahagoni and E. aquea) than when incubating $C$. papaya alone. Additionally, mixtures resulted in non-additive effects for all $\mathrm{CH}_{4}$-related parameters of the order of $2-15 \%$ deviation from the expected value $(P<0 \cdot 01)$. This means that, by combining these plants, $\mathrm{CH}_{4}$ in relation to the fermentative capacity was lower than that predicted when assuming the linearity of the effects. Similar non-additive effects of combining $C$. papaya with the other plants were found for $\mathrm{NH}_{3}$ concentrations but not for SCFA concentrations. In conclusion, using mixtures of high-quality plants and high-phenolic plants could be one approach to $\mathrm{CH}_{4}$ mitigation; however, this awaits in vivo confirmation.
\end{abstract}

\section{Key words: Ruminants: Methanogenesis: Phenolic compounds: Forage}

Various investigations are currently under way to identify and test means for mitigating $\mathrm{CH}_{4}$ emissions that originate from ruminants due to the activity of methanogenic archaea during feed fermentation ${ }^{(1)}$. As a product of fermentative digestion, $\mathrm{CH}_{4}$ emission levels depend considerably on the quantity and composition of feeds consumed ${ }^{(2)}$. The potential of mitigating $\mathrm{CH}_{4}$ emissions by the extracts of phenolic compounds, which are synthesised in the intermediary metabolism of plants, has been demonstrated experimentally ${ }^{(3-5)}$. Also, the direct inclusion of plants containing phenolics in ruminant diets reduced $\mathrm{CH}_{4}$ emissions compared with control diets, both in vitro ${ }^{(6)}$ and in vivo ${ }^{(7,8)}$.

A major drawback in implementing diets with doses of phenolics aimed at reducing $\mathrm{CH}_{4}$ emissions is often a decline in the digestibility of the feed and therewith the productivity of the animals ${ }^{(9)}$, even at dosages where toxic side effects are excluded. As a consequence, there are often no or only small declines in $\mathrm{CH}_{4}$ per unit of digested feed and, therefore, food produced. Analysing a larger dataset by principal components analysis illustrated that plants with high forage quality are arranged opposite to those with a high $\mathrm{CH}_{4-}^{-}$ mitigating potential ${ }^{(10)}$. This indicates that achieving both goals simultaneously is difficult. Studies by Tiemann et $a l^{(8,11)}$, where low-quality tropical Brachiaria hay was combined with highly tanniferous shrub forage, have shown that any reduction in $\mathrm{CH}_{4}$ was associated with a correspondingly lower utilisation of dietary energy. This may be different when high-phenolic plants are combined with high-quality feeds. So far, studies specifically designed to measure the additivity or non-additivity of the effects (i.e. non-linear effects, elsewhere also defined as associative effects ${ }^{(12)}$ when investigating combinations of plants) in the context of ruminal $\mathrm{CH}_{4}$ emissions are scarce.

In the present study, we hypothesised that combining plants characterised by different phenolic profiles with one having high quality would have general favourable

Abbreviations: CT, condensed tannins; HT, hydrolysable tannins; NTP, non-tannin phenolics; SCFA, short-chain fatty acids.

*Corresponding author: F. Leiber, fax +41 44632 1128, email florian.leiber@usys.ethz.ch 
non-additive effects in terms of lower $\mathrm{CH}_{4}$ emission relative to the productivity of ruminal fermentation in vitro. We specifically looked at in vitro $\mathrm{CH}_{4}$ emissions per unit of SCFA or total gas as indicators of fermentation productivity. For this purpose, the leaves of four tropical plants were selected as model forages. Carica papaya was chosen as forage of high quality. Clidemia birta, Swietenia mahagoni and Eugenia aquea represented forages containing appreciable amounts of total phenolics but a different phenolic profile. These plants were selected on the basis of a previous screening experiment ${ }^{(10)}$. With this kind of experimental design, it is possible to demonstrate in vitro the non-additivity of the properties of differing forages, which in the best case can be used as a first step towards developing forage-based diets with lowered methanogenic potential without similarly impaired ruminal fermentation efficiency. However, with this approach, it is not possible to distinguish whether the resulting effects are dose-response effects of any single compound or interaction effects of different compounds. Although in vitro evidence has a limited applicability for the situation in vivo, it provides additional information about the occurrence of such complementary effects of feeds with differing profiles in plant secondary compounds on nutrition processes in ruminants, which have already been described in vivo in another context ${ }^{(13)}$. The present study aimed to indicate areas on which future in vivo experiments could focus.

\section{Materials and methods}

\section{Experimental design and plant material}

All plant samples were incubated both individually and in all possible mixtures (Table 1). The mixtures consisted of two, three or four plants represented in equal proportions. This resulted in a total of fifteen treatments. The leaves of C. papaya were characterised by high crude protein contents, low contents of fibre and lignin as well as favourably high in vitro organic matter digestibility ${ }^{(10)}$. This differed clearly from the properties of the three high-phenolic plants selected

Table 1. Treatment formulation and amounts (mg DM) of plants incubated in vitro

\begin{tabular}{lcccc}
\hline Treatments & $\mathrm{P}$ & $\mathrm{C}$ & $\mathrm{S}$ & $\mathrm{E}$ \\
\hline $\mathrm{P}$ & 200 & - & - & - \\
$\mathrm{C}$ & - & 200 & - & - \\
$\mathrm{S}$ & - & - & 200 & - \\
$\mathrm{E}$ & - & - & - & 200 \\
$\mathrm{PC}$ & 100 & 100 & - & - \\
$\mathrm{PS}$ & 100 & - & 100 & - \\
$\mathrm{PE}$ & 100 & - & - & 100 \\
$\mathrm{CS}$ & - & 100 & 100 & - \\
$\mathrm{CE}$ & - & 100 & - & 100 \\
$\mathrm{SE}$ & - & - & 100 & 100 \\
PCS & 67 & 67 & 67 & - \\
PCE & 67 & 67 & - & 67 \\
PSE & 67 & - & 67 & 67 \\
CSE & - & 67 & 67 & 67 \\
PCSE & 50 & 50 & 50 & 50 \\
\hline
\end{tabular}

P, Carica papaya; C, Clidemia hirta; S, Swietenia mahagoni; E, Eugenia aquea. that were rich in phenolics (7- to 9-fold levels of total phenolics compared with C. papaya). Concerning the phenolic profile, C. birta is rich in hydrolysable tannins (HT), S. mabagoni contains particularly high levels of condensed tannins (CT) as well as appreciable levels of HT and non-tannin phenolics (NTP), and E. aquea is especially rich in NTP and lignin. The selected plants were considered to be suitable models for the purpose of comparing plants with quite similar contents but different categories of phenolic compounds. Even though not very common globally and not used as the sole feed, the leaves of C. papaya, C. hirta, S. mahagoni and $E$. aquea are used either as ruminant feeds in rural areas (C. papaya and C. hirta) or as traditional veterinary medicinal plants in the areas around Bogor on the Java island of Indonesia ${ }^{(10)}$. Since the present study aimed at the basic question of non-additivity when combining single forages instead of formulating complex diets, no standardisation was applied for other nutrients such as crude protein or neutraldetergent fibre, although this might have interfered with the effects of phenolic compounds.

The leaves of the experimental plants were collected in November 2008 from the area of the Indonesian Research Institute for Animal Production, Ciawi, Bogor, located at an elevation of $350 \mathrm{~m}$ above sea level. About $3 \mathrm{~kg}$ fresh matter of each plant species was sampled. Each sample consisted of leaves from several individual plants from the same species. The samples were immediately air-dried in a greenhouse for $2 \mathrm{~d}$, followed by oven-drying overnight at $50^{\circ} \mathrm{C}$. After drying, the samples were ground to pass a $1 \mathrm{~mm}$ sieve, and then subjected to chemical analysis and in vitro incubation. As the same batches of the four feeds as those tested in an earlier study were used in the present study, no new compositional analyses were performed and the analytical procedures have been described in detail in Jayanegara et al. ${ }^{(10)}$. Briefly, for C. papaya, C. hirta, S. mahagoni and E. aquea, the following concentrations (g/kg DM) were analysed: crude protein, 386, 129, 112 and 199; neutral-detergent fibre, 155, 232, 281 and 479; total extractable phenolics, 25, 216, 207 and 169; total tannins, 8, 212, 138 and 67; CT, 0, 10, 86 and 40; HT, 8, 202, 52 and 27; NTP, 17, 4, 69 and $102^{(10)}$.

\section{In vitro procedure and analyses}

An amount of $200 \mathrm{mg}$ DM of individual plants or mixtures was incubated with $10 \mathrm{ml}$ of rumen fluid and $20 \mathrm{ml}$ of buffer solution using the Hohenheim gas test apparatus ${ }^{(14)}$ with modified syringes ${ }^{(15)}$. The latter have two outlets, in which the first outlet is designed for filling and emptying the liquid phase and the second allows sampling from the gas phase. Incubation was carried out for $24 \mathrm{~h}$ at $39^{\circ} \mathrm{C}$ in four subsequent runs, comprising two treatment replicates per run $(n 8)$. This was complemented for each run by three syringes without feed, with standard hay and concentrate. Both standard hay and concentrate were obtained from the Institute of Animal Nutrition, University of Hohenheim, Stuttgart, Germany. Data on the expected amounts of total gas produced from incubation of the standards were used in comparison with those actually measured, in order to monitor whether incubation 
went in a normal way and to adjust total gas ${ }^{(14)}$. The donor of rumen fluid was a rumen-cannulated lactating Brown Swiss cow; the fluid was taken before the morning feeding. In order to prevent any previous adaptive processes to the phenolics, the cow received hay made from a ryegrass-whiteclover ley with ad libitum access and $0.5 \mathrm{~kg} / \mathrm{d}$ of dairy cow concentrate (UFA 149, UFA AG). The cow was cared for according to the Swiss guidelines for animal welfare. After collection, rumen fluid was strained through four layers of gauze ( $1 \mathrm{~mm}$ pore size, Type 17 ; MedPro Novamed AG) in order to filter out any feed particles.

The volume of fermentation gas produced during $24 \mathrm{~h}$ of incubation was read from the calibrated scale on each glass syringe. The liquid phase in each syringe was decanted. Subsequently, $0 \cdot 15 \mathrm{ml}$ of fermentation gas were withdrawn with a Hamilton syringe (Hamilton AG) through a gas-tight septum covering the outlet. This gas sample was injected into a gas chromatograph (Model 5890 Series II; Hewlett Packard) for measuring $\mathrm{CH}_{4}$ and $\mathrm{H}_{2}$ concentrations. $\mathrm{NH}_{3}$ and $\mathrm{pH}$ of the incubation liquid were determined with a potentiometer (Model 632; Metrohm) equipped with the corresponding electrodes. Total $\mathrm{NH}_{3}$ was calculated from $\mathrm{NH}_{3}$ concentration and the volume of the incubation liquid. SCFA were analysed using HPLC (LaChrom, L-7000 series; Hitachi Limited) equipped with an UV-VIS detector, read at $210 \mathrm{~nm}^{(10)}$. Total viable bacterial and protozoal numbers were counted by direct microscopic counting using Bürker counting chambers (Blau Brand) with depths of 0.02 and $0.1 \mathrm{~mm}$, respectively. For bacterial counting, samples were treated with Hayem solution $\left(\mathrm{HgCl}_{2}, 2.5 \mathrm{mg} / \mathrm{ml} ; \mathrm{Na}_{2} \mathrm{SO}_{4}, 25 \mathrm{mg} / \mathrm{ml} ; \mathrm{NaCl}, 5 \cdot 0 \mathrm{mg} / \mathrm{ml}\right)$. Viability of bacteria was accounted for by counting only moving individuals. Before protozoal counting, samples were treated with $1: 10$ diluted formalin $(40 / 100, \mathrm{w} / \mathrm{v}$ in water). Only intact protozoa and no fragments were counted.

\section{Calculations and statistical analysis}

Following Menke \& Steingass ${ }^{(14)}$, gas production from the blank was subtracted from all samples incubated to obtain the net gas production. Subsequently, gas production from the hay standard ( $44.43 \mathrm{ml}$ gas $/ 200 \mathrm{mg}$ DM; $24 \mathrm{~h}$ incubation) was divided by the measured net value of the hay standard to provide the correction factor $F_{\mathrm{H}}$. Similarly, gas production from the concentrate standard $(65.18 \mathrm{ml} / 200 \mathrm{mg} \mathrm{DM} ; 24 \mathrm{~h}$ incubation) was divided by the measured net gas production of the concentrate standard to provide $F_{\mathrm{C}}$. The average value of $F_{\mathrm{H}}$ and $F_{\mathrm{C}}$ was used for the adjustment. Data on $\mathrm{CH}_{4}$ and $\mathrm{H}_{2}$ concentrations were transformed into volume $(\mathrm{ml}, \mu \mathrm{l})$ data by multiplying the measured concentrations with the measured total gas volume. To get a direct meaningful relationship of $\mathrm{CH}_{4}$ to SCFA, molar amounts were calculated by assuming a density of $0.67 \mathrm{~kg} / \mathrm{m}^{3}$ for $\mathrm{CH}_{4}$ gas at $1 \cdot 013$ bar and $16^{\circ} \mathrm{C}^{(16)}$.

The data generated were subjected to a mixed model of ANOVA. Incubation runs, serving as a block in the ANOVA model, were considered as random effects, while plant treatments were included as fixed effects. If fixed effects were significant at $P<0.05$, multiple comparisons among means were made using Tukey's post hoc test. Before ANOVA, bacterial and protozoal counts were transformed into their logarithmic units. All statistical analyses were performed using SPSS statistical software version $17.0^{(17)}$.

The main purpose of the experiment was to reveal the presence of non-additive effects. Non-additive effects were defined as the deviations of the observed values (obtained by measurements) from the expected values (calculated as arithmetic means of the values obtained by the respective individual plant incubations). These differences were analysed for all plant mixtures using a paired $t$ test and presented as (observed value - expected value)/expected value $\times 100 \%$ following Niderkorn et al. ${ }^{(12)}$. All expected ratio values were calculated by the actually measured values for each individual incubation. This means that the expected values were not calculated from the already averaged ratio values, as shown in Tables 2 and 3. For the ratio of $\mathrm{CH}_{4}$ :total gas $(\mathrm{ml} / \mathrm{l})$, the expected value was calculated as $\left(\left(\mathrm{CH}_{4}\right.\right.$ plant $_{1}+\mathrm{CH}_{4}$ plant $\left._{i-n}\right) /$ $n) /\left(\left(\right.\right.$ total gas plant $1+$ total gas plant $\left.\left._{i-n}\right) / n\right)$, where $n$ is the number of involved plant species. The same principle was applied for calculating the expected value for the ratio of $\mathrm{CH}_{4}: \mathrm{SCFA}(\mathrm{mmol} / \mathrm{mol})$.

\section{Results}

\section{Effects of plants and combinations of plants on in vitro fermentation}

The total SCFA amount was superior when $C$. papaya was incubated compared with the other three plants $(P<0.05)$, where $E$. aquea was inferior to $C$. hirta and $S$. mahagoni (Table 2). The acetate:propionate ratio was shifted towards acetate when E. aquea was incubated compared with the other three forages $(P<0 \cdot 05)$. Combining the different forages resulted in values for SCFA production and proportions of acetate and propionate being always intermediate between those obtained from individual incubations. For the molar proportions of butyrate, valerate and their iso forms, the effects were less clear.

Total gas produced from incubation with $C$. papaya was twice that with $C$. hirta and $S$. mahagoni $(P<0.05)$, and the latter two plants produced twice as much total gas compared with E. aquea $\left(P<0.05\right.$; Table 3). The volumes of $\mathrm{CH}_{4}$ and $\mathrm{H}_{2}$ (which on average amounted to only about $0 \cdot 1 \%$ of that of $\mathrm{CH}_{4}$ ) varied, when total gas varied. Nevertheless, the gas composition differed among the treatments. Incubating S. mahagoni led to the lowest $\mathrm{CH}_{4}$ :total gas ratio among the individual plants $(P<0 \cdot 05)$, while incubating $C$. papaya produced twice the level. The lowest $\mathrm{H}_{2}$ :total gas proportion was found when E. aquea $(40 \mu \mathrm{l} / \mathrm{l})$ was incubated and the highest with $C$. papaya $(110 \mu \mathrm{l} / 1 ; P<0.05$; data not shown). The amounts of $\mathrm{CH}_{4}$ in relation to the amounts of SCFA after incubation differed $(P<0.05)$ between each of the forage species, and were ranked in the order of $C$. papaya $>$ C. birta $>S$. mabagoni $>$ E. aquea. The concentration of $\mathrm{NH}_{3}$ in the incubation liquid was highest when C. papaya was incubated alone, whereas the ratio of $\mathrm{NH}_{3}-\mathrm{N}$ :dietary $\mathrm{N}$ was highest with E. aquea incubation and differed $(P<0.05)$ 
Table 2. Effect of plant species or species combinations on in vitro incubation liquid SCFA profiles (observed values, $n$ 8)

\begin{tabular}{|c|c|c|c|c|c|c|c|c|}
\hline \multirow[b]{2}{*}{ Treatments $^{*}$} & \multirow[b]{2}{*}{ Total SCFA $(\mathrm{mmol} / \mathrm{l})$} & \multicolumn{6}{|c|}{ Molar proportion of total SCFA } & \multirow[b]{2}{*}{$\mathrm{C}_{2}: \mathrm{C}_{3}$} \\
\hline & & $\mathrm{C}_{2}$ & $\mathrm{C}_{3}$ & $\mathrm{C}_{4}$ & iso $_{4}$ & $\mathrm{C}_{5}$ & iso $_{5}$ & \\
\hline$P$ & $75 \cdot 7^{\mathrm{i}}$ & $70 \cdot 9^{a}$ & $16 \cdot 7^{d}$ & $8 \cdot 6^{\mathrm{b}, \mathrm{c}}$ & $1.43^{\mathrm{c}}$ & $1 \cdot 24^{c}$ & 1.09 & $4 \cdot 36^{\mathrm{a}}$ \\
\hline C & $50 \cdot 0^{b, c}$ & $73 \cdot 6^{\mathrm{b}, \mathrm{c}, \mathrm{d}}$ & $15 \cdot 4^{\mathrm{a}, \mathrm{b}, \mathrm{c}}$ & $9.0^{\mathrm{C}}$ & $0.59^{a, b}$ & $0.52^{a, b}$ & 0.80 & $4.79^{\mathrm{a}, \mathrm{b}, \mathrm{c}}$ \\
\hline$S$ & $50 \cdot 4^{\mathrm{b}, \mathrm{c}, \mathrm{d}}$ & $74 \cdot 5^{\mathrm{c}, \mathrm{d}}$ & $16 \cdot 3^{\mathrm{b}, \mathrm{c}, \mathrm{d}}$ & $6 \cdot 8^{\mathrm{a}}$ & $0.42^{\mathrm{ab}}$ & $0.91^{\mathrm{b}, \mathrm{c}}$ & 1.02 & $4 \cdot 60^{\mathrm{a}, \mathrm{b}}$ \\
\hline$E$ & $42 \cdot 7^{\mathrm{a}}$ & $74 \cdot 9^{d}$ & $14 \cdot 3^{\mathrm{a}}$ & $8 \cdot 5^{\mathrm{b}, \mathrm{c}}$ & $0.53^{a, b}$ & $0.63^{a, b}$ & $1 \cdot 16$ & $5 \cdot 26^{\mathrm{c}, \mathrm{d}}$ \\
\hline $\mathrm{PC}$ & $60 \cdot 5^{\mathrm{g}, \mathrm{h}}$ & $72 \cdot 0^{\mathrm{a}, \mathrm{b}}$ & $16 \cdot 6^{\mathrm{c}, \mathrm{d}}$ & $8 \cdot 6^{\mathrm{b}, \mathrm{c}}$ & $0 \cdot 82^{a, b}$ & $0.67^{a, b}$ & $1 \cdot 21$ & $4 \cdot 34^{\mathrm{a}}$ \\
\hline PS & $62 \cdot 3^{\mathrm{h}}$ & $73 \cdot 0^{\mathrm{a}, \mathrm{b}, \mathrm{c}, \mathrm{d}}$ & $16 \cdot 4^{\mathrm{c}, \mathrm{d}}$ & $8 \cdot 4^{\mathrm{b}, \mathrm{c}}$ & $0.85^{\mathrm{a}, \mathrm{b}, \mathrm{c}}$ & $0.66^{a, b}$ & 0.80 & $4.47^{a, b}$ \\
\hline $\mathrm{PE}$ & $57 \cdot 4^{\mathrm{f}, \mathrm{g}}$ & $72 \cdot 7^{\mathrm{a}, \mathrm{b}, \mathrm{c}, \mathrm{d}}$ & $16 \cdot 2^{\mathrm{b}, \mathrm{c}, \mathrm{d}}$ & $8 \cdot 6^{\mathrm{b}, \mathrm{c}}$ & $0 \cdot 80^{\mathrm{a}, \mathrm{b}}$ & $0.74^{a, b}$ & 0.97 & $4 \cdot 51^{\mathrm{a}, \mathrm{b}}$ \\
\hline $\mathrm{CS}$ & $50 \cdot 9^{\mathrm{b}, \mathrm{c}, \mathrm{d}}$ & $74 \cdot 5^{c, d}$ & $16 \cdot 0^{\mathrm{b}, \mathrm{c}, \mathrm{d}}$ & $7 \cdot 5^{a, b}$ & $0.53^{a, b}$ & $0.56^{a, b}$ & 0.80 & $4 \cdot 67^{\mathrm{a}, \mathrm{b}, \mathrm{c}}$ \\
\hline $\mathrm{CE}$ & $47 \cdot 0^{a, b}$ & $73 \cdot 9^{b, c, d}$ & $14 \cdot 5^{a}$ & $9 \cdot 3^{\mathrm{c}}$ & $0.66^{a, b}$ & $0.42^{\mathrm{a}}$ & $1 \cdot 19$ & $5 \cdot 11^{\mathrm{c}, \mathrm{d}}$ \\
\hline SE & $46 \cdot 9^{a, b}$ & $74 \cdot 5^{\mathrm{c}, \mathrm{d}}$ & $15 \cdot 4^{\mathrm{a}, \mathrm{b}, \mathrm{c}}$ & $8 \cdot 0^{a, b, c}$ & $0.62^{a, b}$ & $0.57^{a, b}$ & 0.92 & $4.84^{\mathrm{b}, \mathrm{c}, \mathrm{d}}$ \\
\hline PCS & $57 \cdot 5^{f, g}$ & $72 \cdot 7^{\mathrm{a}, \mathrm{b}, \mathrm{c}}$ & $16 \cdot 1^{\mathrm{b}, \mathrm{c}, \mathrm{d}}$ & $8 \cdot 8^{b, c}$ & $1.03^{b, c}$ & $0.55^{a, b}$ & 0.88 & $4.53^{\mathrm{a}, \mathrm{b}}$ \\
\hline PCE & $54 \cdot 8^{\mathrm{d}, \mathrm{e}, \mathrm{f}}$ & $72 \cdot 7^{a, b, c}$ & $16 \cdot 0^{\mathrm{b}, \mathrm{c}, \mathrm{d}}$ & $9 \cdot 0^{c}$ & $0.62^{a, b}$ & $0 \cdot 61^{a, b}$ & $1 \cdot 16$ & $4.56^{a, b}$ \\
\hline PSE & $56 \cdot 4^{\mathrm{e}, \mathrm{f}, \mathrm{g}}$ & $72 \cdot 6^{\mathrm{a}, \mathrm{b}, \mathrm{c}}$ & $15 \cdot 9^{\mathrm{b}, \mathrm{c}, \mathrm{d}}$ & $9 \cdot 1^{\mathrm{c}}$ & $0.84^{a, b, c}$ & $0.48^{\mathrm{a}}$ & $1 \cdot 17$ & $4.58^{\mathrm{a}, \mathrm{b}}$ \\
\hline CSE & $47 \cdot 7^{\mathrm{b}}$ & $74 \cdot 2^{\mathrm{b}, \mathrm{c}, \mathrm{d}}$ & $15 \cdot 1^{a, b}$ & $8 \cdot 5^{\mathrm{b}, \mathrm{c}}$ & $0.71^{\mathrm{a}, \mathrm{b}}$ & $0.61^{a, b}$ & 0.90 & $4.93^{\mathrm{b}, \mathrm{c}, \mathrm{d}}$ \\
\hline PCSE & $52 \cdot 9^{\mathrm{c}, \mathrm{d}, \mathrm{e}}$ & $73.9^{b, c, d}$ & $15 \cdot 7^{a, b, c, d}$ & $8 \cdot 6^{\mathrm{b}, \mathrm{c}}$ & $0.39^{a}$ & $0.48^{\mathrm{a}}$ & 0.90 & $4 \cdot 71^{\mathrm{a}, \mathrm{b}, \mathrm{c}}$ \\
\hline SEM & 0.83 & 0.16 & 0.11 & $0 \cdot 10$ & 0.039 & 0.028 & 0.044 & 0.038 \\
\hline$P$ & $<0.001$ & $<0.001$ & $<0.001$ & $<0.001$ & $<0.001$ & $<0.001$ & 0.449 & $<0.001$ \\
\hline
\end{tabular}

$\mathrm{C}_{2}$, acetate; $\mathrm{C}_{3}$, propionate; $\mathrm{C}_{4}$, butyrate; $\mathrm{C}_{5}$, valerate; $\mathrm{C}_{2}: \mathrm{C}_{3}$, acetate:propionate ratio.

a-i Mean values within a column with unlike superscript letters were significantly different $(P<0.05)$

${ }^{\star}$ C, Clidemia hirta; E, Eugenia aquea; P, Carica papaya; S, Swietenia mahagoni.

from the values measured with the other plants. There were some differences in the $\mathrm{pH}$ of the incubation liquid, but not $(P>0.05)$ in the logarithmic counts of viable bacteria and protozoa across all experimental treatments (data not shown).

In general, combining either C. hirta, S. mabagoni or $E$. aquea with $C$. papaya in binary mixtures resulted in lower total gas production compared with the incubation of C. papaya alone $(P<0 \cdot 05)$. $\mathrm{CH}_{4}$-related variables $\left(\mathrm{CH}_{4}\right.$, $\mathrm{CH}_{4}$ :SCFA and $\mathrm{CH}_{4}$ :total gas) were also reduced by mixing these plants $(P<0.05)$ compared with the incubation of C. papaya alone. The mixing of $C$. hirta and/or E. aquea with $S$. mahagoni resulted in a lower $(P<0.05) \mathrm{CH}_{4}$ :total gas ratio than all mixtures including $C$. papaya. Furthermore, all plant mixtures caused a decrease in the ratio of $\mathrm{CH}_{4}$ :SCFA compared with pure $C$. papaya incubation $(P<0.05)$. The lowest ratios were found with the mixtures containing no C. papaya; however, this resulted in a very low level of SCFA production. The mixtures containing $C$. papaya increased ruminal $\mathrm{NH}_{3}$ concentrations compared with the mixtures without this plant.

\section{Non-additive effects of using plant mixtures}

No non-additive effects on total SCFA concentration were observed when combining any plant species (Table 4). Binary mixtures including C. papaya did not result ( $P>0.05)$ in non-additive effects on total gas production. However, when $C$. papaya was combined with two or all three highphenolic plants, non-additive effects $(P<0.05)$ on gas production were observed. Combining $C$. papaya with any

Table 3. Effect of plant species or species combinations on in vitro rumen fermentation measurements (observed values, $n$ 8)

\begin{tabular}{|c|c|c|c|c|c|c|c|c|}
\hline Treatments* & $\begin{array}{l}\text { Total gas } \\
(\mathrm{ml})\end{array}$ & $\begin{array}{r}\mathrm{CH}_{4} \\
(\mathrm{ml})\end{array}$ & $\begin{array}{l}\mathrm{H}_{2} \\
(\mu \mathrm{l})\end{array}$ & $\begin{array}{c}\mathrm{CH}_{4}: \text { total gas } \\
(\mathrm{ml} / \mathrm{l})\end{array}$ & $\begin{array}{l}\mathrm{CH}_{4}: \mathrm{SCFA} \\
(\mathrm{mmol} / \mathrm{mol})\end{array}$ & $\mathrm{pH}$ & $\begin{array}{c}\mathrm{NH}_{3} \\
(\mathrm{mmol} / \mathrm{l})\end{array}$ & $\begin{array}{c}\mathrm{NH}_{3}-\mathrm{N} \text { :dietary } \mathrm{N} \\
(\mathrm{mg} / \mathrm{mg})\end{array}$ \\
\hline $\mathrm{P}$ & $44 \cdot 3^{g}$ & $8 \cdot 1^{i}$ & $5 \cdot 1^{f}$ & $181^{i}$ & $149^{\mathrm{j}}$ & $7 \cdot 38^{\mathrm{c}, \mathrm{d}}$ & $27 \cdot 3^{h}$ & $0.93^{c, d}$ \\
\hline $\mathrm{S}$ & $22 \cdot 7^{\mathrm{c}, \mathrm{d}}$ & $2 \cdot 1^{\mathrm{c}, \mathrm{d}, \mathrm{e}}$ & $1 \cdot 2^{a, b, c}$ & $91^{\mathrm{a}}$ & $57^{\mathrm{b}, \mathrm{c}}$ & $7 \cdot 31^{\mathrm{b}, \mathrm{c}}$ & $8 \cdot 4^{a}$ & $0.98^{\mathrm{c}, \mathrm{d}}$ \\
\hline$E$ & $10 \cdot 4^{a}$ & $1 \cdot 3^{a}$ & $0.4^{\mathrm{a}}$ & $122^{\mathrm{d}, \mathrm{e}}$ & $42^{\mathrm{a}}$ & $7 \cdot 34^{c}$ & $10 \cdot 7^{c, d}$ & $1.41^{\mathrm{e}}$ \\
\hline $\mathrm{PC}$ & $33 \cdot 1^{f}$ & $4 \cdot 7^{\mathrm{h}}$ & $3 \cdot 0^{e, f}$ & $143^{g}$ & $109^{i}$ & $7 \cdot 34^{c}$ & $14 \cdot 1^{\mathrm{f}, \mathrm{g}}$ & $0.72^{a}$ \\
\hline PS & $32 \cdot 6^{f}$ & $4 \cdot 5^{h}$ & $2 \cdot 9^{e, f}$ & $137^{\mathrm{f}, \mathrm{g}}$ & $100^{h}$ & $7 \cdot 32^{b, c}$ & $13 \cdot 5^{e, f}$ & $0 \cdot 71^{a}$ \\
\hline PE & $27 \cdot 9^{e}$ & $4 \cdot 5^{h}$ & $2 \cdot 2^{\mathrm{d}, \mathrm{e}}$ & $159^{h}$ & $107^{\mathrm{h}, \mathrm{i}}$ & $7 \cdot 38^{c, d}$ & $15 \cdot 8^{g}$ & $0.86^{b, c}$ \\
\hline $\mathrm{CS}$ & $21 \cdot 5^{c}$ & $2 \cdot 3^{\mathrm{d}, \mathrm{e}}$ & $1 \cdot 1^{a, b, c}$ & $104^{b}$ & $61^{\mathrm{c}, \mathrm{d}}$ & $7 \cdot 26^{a, b}$ & $8 \cdot 3^{a}$ & $0.90^{c}$ \\
\hline $\mathrm{CE}$ & $15 \cdot 3^{b}$ & $1 \cdot 8^{\mathrm{b}, \mathrm{c}}$ & $1 \cdot 5^{b, c, d}$ & $115^{c, d}$ & $53^{b, c}$ & $7 \cdot 32^{b, c}$ & $9 \cdot 1^{a, b, c}$ & $1.05^{d}$ \\
\hline SE & $15 \cdot 9^{b}$ & $1 \cdot 7^{\mathrm{a}, \mathrm{b}}$ & $0.9^{a, b, c}$ & $103^{b}$ & $49^{a, b}$ & $7 \cdot 34^{c}$ & $8 \cdot 5^{a, b}$ & $1.05^{d}$ \\
\hline PCS & $28 \cdot 3^{\mathrm{e}}$ & $3 \cdot 6^{\mathrm{g}}$ & $1 \cdot 6^{b, c, d}$ & $127^{e, f}$ & $87^{g}$ & $7 \cdot 33^{b, c}$ & $10 \cdot 3^{b, c, d}$ & $0.65^{a}$ \\
\hline PCE & $24 \cdot 1^{d}$ & $3.5^{\mathrm{g}}$ & $1 \cdot 0^{\mathrm{a}, \mathrm{b}, \mathrm{c}}$ & $142^{g}$ & $87^{g}$ & $7 \cdot 38^{c, d}$ & $12 \cdot 0^{\mathrm{d}, \mathrm{e}}$ & $0.77^{a, b}$ \\
\hline PSE & $24 \cdot 5^{d}$ & $3 \cdot 3^{f, g}$ & $1 \cdot 3^{a, b, c, d}$ & $132^{e, f}$ & $80^{f, g}$ & $7 \cdot 35^{\mathrm{c}, \mathrm{d}}$ & $11 \cdot 4^{d}$ & $0.76^{a, b}$ \\
\hline CSE & $16 \cdot 9^{b}$ & $1 \cdot 9^{\mathrm{b}, \mathrm{c}, \mathrm{d}}$ & $0.9^{a, b, c}$ & $111^{b, c}$ & $55^{b, c}$ & $7 \cdot 33^{b, c}$ & $9 \cdot 0^{a, b, c}$ & $1.04^{d}$ \\
\hline SEM & 0.78 & $0 \cdot 16$ & 0.44 & 2.4 & $5 \cdot 1$ & 0.01 & 0.47 & 0.022 \\
\hline$P$ & $<0.001$ & $<0.001$ & $<0.001$ & $<0.001$ & $<0.001$ & $<0.001$ & $<0.001$ & $<0.001$ \\
\hline
\end{tabular}

${ }^{\mathrm{a}-\mathrm{j}}$ Mean values within a column with unlike superscript letters were significantly different $(P<0.05)$

${ }^{\star}$ C, Clidemia hirta; E, Eugenia aquea; P, Carica papaya; S, Swietenia mahagoni. 
Table 4. Non-additivity of the effects of the plant mixtures (difference in observed values to expected values, in percentage of the expected valuest) on in vitro rumen fermentation parameters $(n 8)$

\begin{tabular}{|c|c|c|c|c|c|c|c|c|}
\hline Treatmentsł & Total SCFA & Total gas & $\mathrm{CH}_{4}$ & $\mathrm{CH}_{4}: \mathrm{SCFA}$ & $\mathrm{CH}_{4}$ :total gas & $\mathrm{pH}$ & $\mathrm{NH}_{3}$ & $\mathrm{NH}_{3}-\mathrm{N}$ :dietary $\mathrm{N}$ \\
\hline PC & $-3 \cdot 1$ & -0.5 & $-10 \cdot 1^{\star \star}$ & $-6 \cdot 9$ & $-9 \cdot 6^{\star \star \star}$ & $0.6^{*}$ & $-22 \cdot 3^{\star \star}$ & $-22 \cdot 2^{\star \star \star}$ \\
\hline PS & -0.4 & -3.0 & $-12 \cdot 1^{\star \star \star}$ & $-10.9^{*}$ & $-9 \cdot 4^{\star \star \star}$ & -0.3 & $-24 \cdot 3^{\star \star}$ & $-25 \cdot 8^{\star \star \star}$ \\
\hline PE & $-2 \cdot 5$ & 1.9 & $-5 \cdot 2^{\star \star}$ & $-2 \cdot 2$ & $-7 \cdot 0^{\star \star *}$ & 0.3 & $-16 \cdot 8^{\star \star}$ & $-27 \cdot 0^{\star \star \star *}$ \\
\hline $\mathrm{CS}$ & 1.6 & $-4 \cdot 1^{*}$ & -1.4 & $-2 \cdot 7$ & 2.9 & 0.0 & $-4 \cdot 0$ & $-4 \cdot 7$ \\
\hline CE & $1 \cdot 8$ & $-5 \cdot 8$ & $-6 \cdot 0$ & $-7 \cdot 7^{\star}$ & 0.0 & 0.7 & $-6 \cdot 8$ & $-9 \cdot 8$ \\
\hline SE & $1 \cdot 1$ & $-4 \cdot 3^{* *}$ & -1.4 & $-2 \cdot 3$ & 3.0 & 0.2 & $-11 \cdot 4^{\star}$ & $-12 \cdot 3^{*}$ \\
\hline PCS & -1.5 & $-4 \cdot 5^{\text {** }}$ & $-14 \cdot 5^{\star \star \star}$ & $-12 \cdot 8^{\star \star}$ & $-10 \cdot 4^{\star * *}$ & 0.4 & $-31 \cdot 0^{\star \star \star}$ & $-31 \cdot 5^{\star \star \star}$ \\
\hline PCE & $-1 \cdot 8$ & $-5 \cdot 6^{*}$ & $-12 \cdot 5^{\star \star}$ & $-10 \cdot 5^{\star}$ & $-7 \cdot 3^{\star \star \star}$ & $0.9^{*}$ & $-23 \cdot 7^{\star \star \star}$ & $-29 \cdot 2^{\star \star \star}$ \\
\hline PSE & 0.6 & $-5 \cdot 3^{\star *}$ & $-15 \cdot 0^{\star \star \star}$ & $-15 \cdot 2^{\star \star}$ & $-10 \cdot 3^{\star \star \star}$ & 0.0 & $-26 \cdot 3^{\star \star \star}$ & $-32 \cdot 0^{\star \star *}$ \\
\hline CSE & 0.1 & $-8 \cdot 5^{\star \star}$ & -3.7 & -3.7 & 5.4 & $0.6^{\star *}$ & $-3 \cdot 2$ & $-5 \cdot 3$ \\
\hline PCSE & $-2 \cdot 8$ & $-7 \cdot 5^{\star}$ & $-15 \cdot 4^{\star \star \star}$ & $-12 \cdot 6^{\star \star}$ & $-8 \cdot 3^{\star \star \star}$ & $1.5^{\star \star}$ & $-25 \cdot 8^{\star \star \star}$ & $-29 \cdot 8^{\star \star \star *}$ \\
\hline
\end{tabular}

* $P<0.05,{ }^{* *} P<0.01,{ }^{* * *} P<0.001$

† Mean values of the individual plants present in the mixtures incubated individually

‡C, Clidemia hirta; E, Eugenia aquea; P, Carica papaya; S, Swietenia mahagoni.

of the other plants ( $C$. hirta, S. mahagoni and E. aquea) led to non-additive effects (at least at $P<0.01$ ) in terms of $\mathrm{CH}_{4}$ emission, either when expressed as the absolute $\mathrm{CH}_{4}$ amount or as the $\mathrm{CH}_{4}$ :SCFA and $\mathrm{CH}_{4}$ :total gas ratios. Non-additive effects, apparent as negative deviations from the values predicted when assuming additive responses to the plant combinations, were observed for mixtures of two, three or four plants, and ranged from 5 to $15 \%, 2$ to $15 \%$ and 7 to $10 \%$ for $\mathrm{CH}_{4}$, $\mathrm{CH}_{4}$ :SCFA and $\mathrm{CH}_{4}$ :total gas, respectively. In contrast, no non-additive effects $(P>0.05)$ on $\mathrm{CH}_{4}$ emissions were found when combining the high-phenolic plants only, i.e. $C$. hirta, S. mahagoni and E. aquea, in 2- or 3-fold mixtures. For the molar amount of $\mathrm{CH}_{4}$ produced per molar amount of SCFA synthesised, all multiple combinations comprising C. papaya resulted in non-additive effects (at least at $P<0.05$ ). For the binary combinations, such non-additive effects were found only for $C$. papaya together with $S$. mahagoni and for $C$. birta together with E. aquea $(P<0.05)$. With regard to $\mathrm{NH}_{3}$-related variables, non-additive effects (negative deviation; $P<0 \cdot 01$ ) of all mixtures of $C$. papaya combined with the other plants were observed for $\mathrm{NH}_{3}$ and $\mathrm{NH}_{3}-\mathrm{N}$ :dietary $\mathrm{N}$. The magnitude of the effects was considerable with deviations of mostly more than $-20 \%$. No such effect was found with combinations of the high-phenolic plants, except for the mixture of $S$. mahagoni and E. aquea.

\section{Discussion}

In natural environments, ruminants select diets from various forage resources such as grasses, forbs, shrubs and tree leaves. These plants may largely vary in their nutritional composition such as energy, protein, vitamins and minerals, and in contents of plant secondary metabolites. Under such conditions, interactions between different kinds of forages and chemical constituents may occur, which might influence intake behaviour, digestion, well-being and performance ${ }^{(13,18)}$. Niderkorn \& Baumont ${ }^{(19)}$ described that mixing two or more different forages can even result in a different response for various parameters (higher or smaller) from that expected if just considering the average of the effects of the individual plants. Yet few studies have specifically investigated the non-additive effects of dietary ingredients, or plants characterised by specific compounds, on rumen fermentation and digestibility in vitro ${ }^{(20,21)}$ and in vivo ${ }^{(22,23)}$. The results reported so far are quite variable; some mixtures showed non-additive effects (either favourable or unfavourable) and others were simply additive.

There is still particularly little information available on the non-additive effects of mixed feeds on $\mathrm{CH}_{4}$ emissions ${ }^{(24,25)}$ Even less literature is available for mixtures involving plants differing in phenolic profiles ${ }^{(12)}$. This is of a particularly high interest as feeds rich in total phenolics cannot be fed alone and it depends on the nature of the relationship between compounds whether their basic anti-methanogenic potential $^{(26,27)}$ is enforced, unchanged or decreased by the combination with plants of high forage quality. In this context, a favourable non-additive effect would mean that the combination of a high-phenol 'plant $\mathrm{X}$ ' with a high-quality 'plant $\mathrm{Y}$ ' would reduce the anti-methanogenic potential coming from plant $\mathrm{X}$ to a proportionately lesser extent than the feeding value of plant $Y$. This concept is simplistic in a way because it cannot answer the question whether any nonadditive effects found are based on a non-linear doseresponse relationship with a single compound or whether they emerge from an interaction of various plant compounds. However, even though non-linearity cannot be traced back to the level of compounds involved (which may also include secondary compounds other than phenolics), this perspective might indicate the potential of complementarity on the level of forages, which is the relevant level in practical livestock feeding, particularly in smallholder farms of developing tropical countries.

\section{Non-additive effects of plant mixtures on ruminal methane formation in relation to the level of ruminal fermentation}

Phenolics have been shown to reduce the population of methanogenic archaea in the rumen ${ }^{(4)}$ and, therefore, to mitigate $\mathrm{CH}_{4}$ emissions. In addition, phenolics interact with other chemical plant constituents such as protein and carbohydrates (both fibre and non-fibre carbohydrates) via hydrogen 
bonds ${ }^{(28)}$. Inhibition of carbohydrate digestion leads to a lower formation of $\mathrm{H}_{2}$, which is a substrate for methanogenesis ${ }^{(29)}$. If this is the major way to mitigate $\mathrm{CH}_{4}$ emissions, there is no advantage in implementing this supplementation strategy into practical feeding as productivity of the animals is concomitantly hampered. The addition of high-phenolic plants to highquality forages might result in an even larger depression in feed utilisation as nutrients of an inherently higher digestibility might be transformed into indigestible compounds. This was confirmed in the present study by the adverse non-additive effects found with some mixtures in total gas production. However, such unfavourable non-additive effects mainly occurred for mixtures containing $S$. mahagoni, which is rich in CT content (numerically also for the mixture with $C$. papaya). Apart from the inhibitory effects of CT on the growth and activity of rumen micro-organisms and the enzymes secreted ${ }^{(30)}$, a stable complex between CT and other chemical constituents $^{(11,31)}$ might explain non-additive effects which decrease fermentative activity in combinations including $S$. mahagoni. The SCFA amounts did not show this effect even in combinations including S. mahagoni. This indicates that the hypothesis that combinations with high-phenolic forages cause non-additive decreases in ruminal productivity is neither fully supported nor disproved by the present results. However, the NTP in E. aquea are likely to possess no or a smaller binding capability. Also, complexes with HT are degradable under ruminal conditions ${ }^{(30)}$, which is relevant for $C$. hirta being rich in HT. However, it should be noted that $C$. hirta, when fed at a high proportion ( 0.5 parts of the total ration; air-dry basis), may lead to hepato- and nephrotoxicity and be associated with gastroenteritis in goats as HT may be absorbed ${ }^{(32)}$.

Concerning $\mathrm{CH}_{4}$ production relative to total gas or SCFA, substantial non-additive effects were found when incubating C. papaya together with the high-phenolic plants or their mixtures (not significant for some binary combinations concerning SCFA). Even though there could be a certain bias in total gas, as some of the gas could be $\mathrm{CO}_{2}$ released from the buffer, both variables pointed to the same direction and thus indicate that methanogenesis was generally more decreased than fermentation productivity when adding the highphenolic plants to $C$. papaya. It appears that, in combination with a high-quality plant, the phenolic compounds inhibit $\mathrm{CH}_{4}$ production more than expected but not at the cost of a more than proportionate impairment of ruminal productivity. In comparison with a high-phenolic plant, a high-quality plant containing low levels of phenolics might not be affected as much in the forage value, whereas the phenolics are still able to exert their direct anti-methanogenic property. This means that the stoichiometry of $\mathrm{CH}_{4}$ formation might be affected. If $\mathrm{CH}_{4}$ formation decreases more than the amounts of either total gas or SCFA, both indicating fermentative productivity, there has to be an alternative sink for the emerging $\mathrm{H}_{2}$. The $\mathrm{H}_{2}$ concentrations in the present study were lower by a factor of 1000 compared with $\mathrm{CH}_{4}$, which is in accordance with other studies and makes it generally difficult to explain alterations in the concentration of $\mathrm{CH}_{4}$ with those in $\mathrm{H}_{2}{ }^{(33)}$. The concentration of $\mathrm{H}_{2}$ was never increased in treatments with negative non-additive effects on $\mathrm{CH}_{4}$ traits. For the combination with the strongest non-additive effects on $\mathrm{CH}_{4}$ (C.papaya, S. mahagoni and E. aquea), the amount of gaseous $\mathrm{H}_{2}$ also underwent a negative non-additive effect. Thus, there seemed to have been generally less $\mathrm{H}_{2}$ present in the incubation unit. Lower ruminal $\mathrm{H}_{2}$ concentrations can be a consequence of increased ruminal propionate formation ${ }^{(33)}$. However, this was not the case with the treatments discussed here. A shortcoming of the present study is that the concentrations of nutrients serving as fermentation substrates alter too much between the different forage combinations and thus do not allow for clear stoichiometric comparisons. Furthermore, non-phenolic plant secondary compounds, such as papain in the papaya leaves, that have not been measured could have interfered. Although the reasons for this disparity of non-additive effects remain unclear, the results of the present study might offer opportunities to develop diets that are concomitantly effective for production and $\mathrm{CH}_{4}$ mitigation.

According to Niderkorn et al. ${ }^{(12)}$ and Robinson et al. ${ }^{(21)}$ non-additive effects of feeds on total gas production in vitro may even be clearly more pronounced after a shorter incubation time of 3.5 or $8 \mathrm{~h}$, when compared with $24 \mathrm{~h}$. A lack of significant non-additive effects on $\mathrm{CH}_{4}$ at $24 \mathrm{~h}$ of incubation was also observed by Goel et $a l^{(34)}$. In that study, combining different levels of the leaves from Carduus pycnocephalus, a plant containing phenolics in unknown concentration, with hay or concentrate did not lead to differences between the observed and expected values for in vitro $\mathrm{CH}_{4}$ emissions. The time effect, however, was not measured in the present study, and all effects found were present after $24 \mathrm{~h}$.

Almost no non-additive effects were found for mixtures of the high-phenolic plants except with regard to $\mathrm{CH}_{4}$ :total gas and $\mathrm{CH}_{4}$ :SCFA. Hypothetically, non-additive effects for mixtures of plants containing high concentrations of different phenols could be significant in two extreme cases: either the effects of different phenolics are mutually strengthening their activity, which would result in less $\mathrm{CH}_{4}$ than expected from incubating individual feeds, or they would counterbalance each other, which would result in the opposite. The response pattern in non-additive effects on $\mathrm{CH}_{4}$ found in the present study suggests that such effects are stronger when combining individual plants that are distinctly different in their general $\mathrm{CH}_{4}$ production potential than when combining forages containing similarly high levels of potentially $\mathrm{CH}_{4}$-inhibiting constituents. The latter plants already produced low $\mathrm{CH}_{4}$ emissions $\left(2.5,2.1\right.$ and $1.3 \mathrm{ml} \mathrm{CH}_{4} / 200 \mathrm{mg} \mathrm{DM}$ with C. birta, $S$. mahagoni and E. aquea, respectively, when incubated alone. This favourably compares with the levels of $2 \cdot 7,1.6$ and $1.0 \mathrm{ml} \mathrm{CH}_{4} / 200 \mathrm{mg}$ DM described earlier in Jayanegara et $\left.a l{ }^{(10)}\right)$. In both experiments, this was far below the level found with C. papaya ( 8.1 and $7.4 \mathrm{ml} \mathrm{CH}_{4} / 200 \mathrm{mg} \mathrm{DM}$, respectively). Even though the high-phenolic plants differed in their phenolic profiles, $\mathrm{CH}_{4}$ production potential seems to be especially determined by total phenolic contents rather than by the specific phenolic fraction (NTP, CT or HT) ${ }^{(10)}$ or other potentially effective compounds.

Generally, the incubations resulted in SCFA concentrations and a $\mathrm{pH}$ that are comparable with other experiments incubating high-phenolic feeds ${ }^{(10,35)}$. The resulting $\mathrm{pH}$ was high, but 
according to Van Kessel \& Russell ${ }^{(36)}$, this should not have impaired methanogenesis. However, since the $\mathrm{pH}$ in the rumen is expected to be clearly lower in vivo, this is one factor which makes it necessary to confirm the results also in in vivo experiments.

\section{Non-additive effects of plant mixtures on ruminal ammonia formation}

The non-additive effects of the plant mixtures on $\mathrm{NH}_{3}$ variables followed the pattern found with the $\mathrm{CH}_{4}$-related variables, i.e. they were significant and negative for the mixtures containing $C$. papaya, and even to a higher magnitude than the $\mathrm{CH}_{4}$ variables. Again, the largely contrasting $\mathrm{NH}_{3}$-generating properties between $C$. papaya $(27 \mathrm{mmol} / \mathrm{l})$ and the plants characterised by high total phenolics (ranging from 8 to $11 \mathrm{mmol} / \mathrm{l}$ ) might have opened room for generating non-additive effects. Mixing forages with high levels of ruminally degradable protein with those elevated in phenolics could therefore be particularly useful to prevent excessive degradation of protein into $\mathrm{NH}_{3}$ as non-additive effects enhance this process. The different groups of phenolics have different protein-binding capacities. While NTP, by definition, do not bind proteins, this is different with both HT and CT, and the bonds formed with CT are particularly resistant ${ }^{(30)}$. However, in the present study, only limited non-additive effects on $\mathrm{NH}_{3}$ production were found when incubating the plants with different types of phenolics alone when compared with incubations of the mixtures with C. papaya.

The general presence of the non-additive effects of plant combinations with different phenolic profiles might also be reflected by the fact that combinations of shrub species that contained different classes of plant secondary metabolites enhanced intake by ruminants ${ }^{(37-39)}$. This could be explained by the attempt to achieve a better nutrient balance, to find the optimum medicinal benefit and to minimise the harmful effects of each of the toxins ${ }^{(13,37,38,40)}$.

\section{Conclusions}

Combining plants containing phenolics with the high-quality leaves of $C$. papaya reduced ruminal $\mathrm{CH}_{4}$ emissions more than predicted from the arithmetic means. This was independent of the respective phenolic profile. These non-additive effects of plant combinations were also apparent in the ratio of $\mathrm{CH}_{4}$ :SCFA. Provided the confirmation of such effects in vivo, this could mean that such mixtures of high-quality and highphenolic forages could help to mitigate $\mathrm{CH}_{4}$ without correspondingly extensively reducing ruminal nutrient utilisation. The mixtures would also prevent excessive degradation of protein into $\mathrm{NH}_{3}$. Whether or not non-additive effects of combining such plants can be recovered in vivo and on which compound interactions they mechanistically rely merits further studies.

\section{Acknowledgements}

A. J. is grateful to the Indonesian Department of National Education for providing a Directorate General of Higher Education
(DIKTI) scholarship. All authors are grateful to Carmen Kunz, Muna Mergani and Irene Zbinden for their assistance during the experimental period. The responsibilities of the authors were as follows: A. J. performed the experiment and statistical analysis, and wrote the manuscript; S. M. revised the manuscript; E. W. collected the experimental plants and advised on the writing of the manuscript; M. K. supervised the project and revised the manuscript; F. L. was the project leader, designed the experiment and revised the manuscript. The authors declare that there is no conflict of interest.

\section{References}

1. McAllister TA, Beauchemin KA, Hao X, et al. (2011) Greenhouse gases in animal agriculture - finding a balance between food and emissions. Anim Feed Sci Technol 166, 167, 1-796.

2. Cottle DJ, Nolan JV \& Wiedemann SG (2011) Ruminant enteric methane mitigation: a review. Anim Prod Sci 51, 491-514.

3. Carulla JE, Kreuzer M, Machmüller A, et al. (2005) Supplementation of Acacia mearnsii tannins decreases methanogenesis and urinary nitrogen in forage-fed sheep. Aust J Agric Res 56, 961-970.

4. Bhatta R, Uyeno Y, Tajima K, et al. (2009) Difference in the nature of tannins on in vitro ruminal methane and volatile fatty acid production and on methanogenic archaea and protozoal populations. J Dairy Sci $\mathbf{9 2}, 5512-5522$.

5. Pellikaan WF, Stringano E, Leenaars J, et al. (2011) Evaluating effects of tannins on extent and rate of in vitro gas and $\mathrm{CH}_{4}$ production using an automated pressure evaluation system (APES). Anim Feed Sci Technol 166, 167, 377-390.

6. Hariadi BT \& Santoso B (2010) Evaluation of tropical plants containing tannin on in vitro methanogenesis and fermentation parameters using rumen fluid. J Sci Food Agric 90 456-461.

7. Animut G, Puchala R, Goetsch AL, et al. (2008) Methane emission by goats consuming diets with different levels of condensed tannins from lespedeza. Anim Feed Sci Technol 144, 212-227.

8. Tiemann TT, Lascano CE, Wettstein H-R, et al. (2008) Effect of the tropical tannin-rich shrub legumes Calliandra calothyrsus and Flemingia macrophylla on methane emission and nitrogen and energy balance in growing lambs. Animal 2, 790-799.

9. Waghorn G (2008) Beneficial and detrimental effects of dietary condensed tannins for sustainable sheep and goat production - progress and challenges. Anim Feed Sci Technol 147, 116-139.

10. Jayanegara A, Wina E, Soliva CR, et al. (2011) Dependence of forage quality and methanogenic potential of tropical plants on their phenolic fractions as determined by principal component analysis. Anim Feed Sci Technol 163, 231-243.

11. Tiemann TT, Lascano CE, Kreuzer M, et al. (2008) The ruminal degradability of fibre explains part of the low nutritional value and reduced methanogenesis in highly tanniniferous tropical legumes. J Sci Food Agric 88, 1794-1803.

12. Niderkorn V, Baumont R, Le Morvan A, et al. (2011) Occurrence of associative effects between grasses and legumes in binary mixtures on in vitro rumen fermentation characteristics. J Anim Sci 89, 1138-1145.

13. Provenza FD, Villalba JJ, Haskell J, et al. (2007) The value to herbivores of plant physical and chemical diversity in time and space. Crop Sci 47, 382-398. 
14. Menke KH \& Steingass H (1988) Estimation of the energetic feed value obtained from chemical analysis and in vitro gas production using rumen fluid. Anim Res Dev 28, 7-55.

15. Soliva CR \& Hess HD (2007) Measuring methane emission of ruminants by in vitro and in vivo techniques. In Measuring Methane Production from Ruminants, pp. 15-31 [HPS Makkar and PE Vercoe, editors]. Dordrecht: Springer.

16. Intergovernmental Panel on Climate Change (IPCC) (2006) Emissions from livestock and manure management. In Guidelines for National Greenhouse Inventories, 4, Agriculture, Forestry and Other Land Use, pp. 10.1-10.87 [HS Eggleston, L Buendia, K Miwa, T Ngara and K Tanabe, editors]. Kanagawa: IGES.

17. SPSS (2008) SPSS Statistics Version 17.O. Chicago: SPSS, Inc.

18. Rogosic J, Estell RE, Ivankovic S, et al. (2008) Potential mechanisms to increase shrub intake and performance of small ruminants in Mediterranean shrubby ecosystems. Small Rum Res 74, 1-15.

19. Niderkorn V \& Baumont R (2009) Associative effects between forages on feed intake and digestion in ruminants. Animal 3, 951-960.

20. Liu JX, Susenbeth A \& Südekum KH (2002) In vitro gas production measurements to evaluate interactions between untreated and chemically treated rice straws, grass hay, and mulberry leaves. J Anim Sci 80, 517-524.

21. Robinson PH, Getachew G \& Cone JW (2009) Evaluation of the extent of associative effects of two groups of four feeds using an in vitro gas production procedure. Anim Feed Sci Technol 150, 9-17.

22. Wang DL, Fan J, Xing F, et al. (2008) Alfalfa as a supplement of dried cornstalk diets: associative effects on intake, digestibility, nitrogen metabolisation, rumen environment and hematological parameters in sheep. Livest Sci 113, 87-97.

23. Zhang XD, Wang JK, Chen WJ, et al. (2010) Associative effects of supplementing rice straw-based diet with cornstarch on intake, digestion, rumen microbes and growth performance of Huzhou lambs. Anim Sci J 81, 172-179.

24. Moss AR, Givens DI \& Garnsworthy PC (1995) The effect of supplementing grass silage with barley on digestibility, in sacco degradability, rumen fermentation and methane production in sheep at two levels of intake. Anim Feed Sci Technol 55, 9-33.

25. Moss AR \& Givens DI (2002) The effect of supplementing grass silage with soya bean meal on digestibility, in sacco degradability, rumen fermentation and methane production in sheep. Anim Feed Sci Technol 97, 127-143.

26. Beauchemin KA, Kreuzer M, O'Mara F, et al. (2008) Nutritional management for enteric methane abatement: a review. Aust J Exp Agric 48, 21-27.

27. Jayanegara A, Kreuzer M \& Leiber F (2012) Meta-analysis of the relationship between dietary tannin level and methane formation in ruminants from in vivo and in vitro experiments. J Anim Physiol Anim Nutr (Berl) 96, 365-375.

28. Silanikove N, Perevolotsky A \& Provenza FD (2001) Use of tannin-binding chemicals to assay for tannins and their negative postingestive effects in ruminants. Anim Feed Sci Technol 91, 69-81.

29. Tavendale MH, Meagher LP, Pacheco D, et al. (2005) Methane production from in vitro rumen incubations with Lotus pedunculatus and Medicago sativa, and effects of extractable condensed tannin fractions on methanogenesis. Anim Feed Sci Technol 123, 124, 403-419.

30. McSweeney CS, Palmer B, McNeill DM, et al. (2001) Microbial interactions with tannins: nutritional consequences for ruminants. Anim Feed Sci Technol 91, 83-93.

31. Makkar HPS (2003) Effects and fate of tannins in ruminant animals, adaptation to tannins, and strategies to overcome detrimental effects of feeding tannin-rich feeds. Small Rum Res 49, 241-256.

32. Murdiati TB, McSweeney CS, Campbell RSF, et al. (1990) Prevention of hydrolysable tannin toxicity in goats fed Clidemia hirta by calcium hydroxide supplementation. J Appl Toxicol 10, 325-331.

33. Janssen PH (2010) Influence of hydrogen on rumen methane formation and fermentation balances through microbial growth kinetics and fermentation thermodynamics. Anim Feed Sci Technol 160, 1-22.

34. Goel G, Makkar HPS \& Becker K (2008) Effects of Sesbania sesban and Carduus pycnocephalus leaves and Fenugreek (Trigonella foenum-graecum L.) seeds and their extracts on partitioning of nutrients from roughage- and concentratebased feeds to methane. Anim Feed Sci Technol 147, 72-89.

35. Tan HY, Sieo CC, Abdullah N, et al. (2011) Effects of condensed tannins from Leucaena on methane production, rumen fermentation and populations of methanogens and protozoa in vitro. Anim Feed Sci Technol 169, 185-193.

36. Van Kessel JAS \& Russell JB (1996) The effect of pH on ruminal methanogenesis. FEMS Microbiol Ecol 20, 205-210.

37. Rogosic J, Pfister JA, Provenza FD, et al. (2006) The effect of activated charcoal and number of species offered on intake of Mediterranean shrubs by sheep and goats. Appl Anim Behav Sci 101, 305-317.

38. Rogosic J, Estell RE, Skobic D, et al. (2007) Influence of secondary compound complementarity and species diversity on consumption of Mediterranean shrubs by sheep. Appl Anim Behav Sci 107, 58-65.

39. Lisonbee LD, Villalba JJ \& Provenza FD (2009) Effects of tannin on selection by sheep of forages containing alkaloids, tannins and saponins. J Sci Food Agric 89, 2668-2677.

40. Makkar HPS, Francis G \& Becker K (2007) Bioactivity of phytochemicals in some lesser-known plants and their effects and potential applications in livestock and aquaculture production systems. Animal 1, 1371-1391. 